\title{
COMUNICACIÓN EN CAMPAÑA. DIRECCIÓN DE CAMPAÑAS ELECTORALES Y MARKETING POLÍTICO Julio César Herrero (Editor) v Max Römer (Coord.) Pearson, Madrid, 2014
}

Graciela Padilla Castillo: Universidad Complutense de Madrid. España.

De los textos recientes sobre campañas electorales, hay en el mercado muchas traducciones. Sin embargo, escritas directamente en castellano, hay pocas como ésta que presentamos: Comunicación en Campaña, editada por Julio César Herrero y coordinada por Max Römer. Se trata de una obra colectiva, escrita por diferentes especialistas, académicos y profesionales que, en 12 capítulos dan buena cuenta del ejercicio de comunicar en campañas electorales.

¿Qué puede encontrar el lector entre sus páginas? Dirección de campañas electorales, demoscopia: la construcción de la agenda, el gabinete de comunicación y las relaciones con los medios, ciberactivismo, el community manager político, la propaganda electoral, la organización de actos políticos, la cobertura informativa de campañas electorales, la imagen de los políticos, el discurso de campaña, los debates políticos televisados y el lobby como instrumento de la democracia, son una radiografía del manejo de las campañas políticas y del marketing electoral desde una óptica directiva, de gestión de recursos.

Elena Flores nos adentra en las diferentes funciones que se viven en una campaña electoral. Para construir la agenda, la propuesta de Fermín Bouza es el manejo de la demoscopia. Enrique Leite nos muestra los intersticios de los gabinetes de comunicación y cómo deben ser las relaciones con los medios de comunicación desde las tendencias de la web 2.0. Carmen Beatriz Fernández toma la batuta que deja Leite en materia 2.0 y propone las tendencias del ciberactivismo desde las plataformas de los partidos políticos y Carlos Hidalgo muestra los trucos que debe manejar el Community manager en materia política.

Max Römer desglosa las fases, los estilos y modos de la propaganda electoral y Carlos Fuente y Gloria Campos dan buena cuenta de la organización de actos políticos. Rafael Barberá y Julio Somoano profundizan acerca de cómo debe ser la cobertura informativa de las campañas electorales y el papel primordial que ejerce la televisión. Siendo la pantalla el lugar donde se crea al político, Jorge Santiago Barnés

\footnotetext{
${ }^{1}$ Graciela Padilla Castillo. gracielp@ucm.es
} 
nos lleva a conocer la imagen de los políticos. Parte de esa construcción de la imagen surge del discurso de campaña. El capítulo escrito por Julio César Herrero y Paula Requeijo plantea cómo redactar y poner en escena un discurso político. Asimismo, Felicísimo Valbuena y Graciela Padilla, dan las recetas de éxito para preparar ese debate de cara a los televidentes.

Finalmente, la democracia requiere de participación permanente, de estar en el lugar oportuno, donde se toman las decisiones. Para poder adentrase en lo institucional, para que el político pueda tener acceso a posicionar sus ideas, requiere del lobby. Allí Carlos Camacho y Gemi José González desarrollan los temas propios del cabildeo o del lobby con miras a crear, sobre la base de los criterios propios de la democracia, esa transparencia gubernamental de la que tanto se habla en estos tiempos. 